University of Nebraska - Lincoln

DigitalCommons@University of Nebraska - Lincoln

$6-2012$

\title{
Finite Element Analysis of the Implantation of a Self-Expanding Stent: Impact of Lesion Calcification
}

\author{
Shijia Zhao \\ University of Nebraska-Lincoln \\ Linxia Gu \\ University of Nebraska-Lincoln, gul@fit.edu \\ Stacey R. Froemming \\ Children's Hospital and Medical Center, Omaha, NE
}

Follow this and additional works at: https://digitalcommons.unl.edu/mechengfacpub

Part of the Mechanical Engineering Commons

Zhao, Shijia; Gu, Linxia; and Froemming, Stacey R., "Finite Element Analysis of the Implantation of a SelfExpanding Stent: Impact of Lesion Calcification" (2012). Mechanical \& Materials Engineering Faculty Publications. 62.

https://digitalcommons.unl.edu/mechengfacpub/62

This Article is brought to you for free and open access by the Mechanical \& Materials Engineering, Department of at DigitalCommons@University of Nebraska - Lincoln. It has been accepted for inclusion in Mechanical \& Materials Engineering Faculty Publications by an authorized administrator of DigitalCommons@University of Nebraska Lincoln. 

Implantation of a Self-Expanding Stent: Impact of Lesion Calcification

Department of Mechanical and Materials Engineering, University of Nebraska-Lincoln,

Lincoln, NE 68588-0656;

Nebraska Center for

Materials and Nanoscience,

Lincoln, NE 68588-0656

e-mail: Igu2@unl.edu

\title{
Stacey R. Froemming \\ Hybrid Catheterization and \\ Electrophysiology Laboratory, \\ Children's Hospital and Medical Center, \\ Omaha, NE 68114-4133
}

\begin{abstract}
In this work, the deployment of a self-expanding stent in a stenosed artery was evaluated through finite element analysis. The three-layered structure of the artery and their material properties were measured and implemented in our computational models. The instant outcomes, including lumen gain, tissue prolapse, and stress distribution, were quantified, and the effect of plaque calcification was evaluated. Results showed that the peak wall stress occurred on the media layer regardless of plaque calcification. The calcified plaque mitigated the tissue prolapse and arterial wall stresses in general, compared with the soft plaque. However, the lesion calcification led to a more severe residual stenosis, dogboning effect, and corresponding edge stress concentrations after stenting, which requires pre-and/or post-surgical management. [DOI: 10.1115/1.4006357]
\end{abstract}

Keywords: self-expanding stent, nitinol, layered artery, calcified plaque, stent-artery interaction, finite element method

\section{Introduction}

Self-expanding Nitinol stents were designed to better withstand the multi-axial dynamic loadings found in the peripheral arteries. They have demonstrated improved 1-year freedom from restenosis after their implantations into stenosed superficial femoral artery (SFA) than percutaneous transluminal angioplasty (PTA) alone, especially for longer lesions [1-3]. However, the calcification of plaque will lower the success rate of stenting in peripheral artery. It has been speculated that wall stress concentration was associated with the occurrence of restenosis [4]. Many physical parameters influence the wall stress distributions, such as dynamics of expansion, stent design, geometry, and properties of tissue, including artery and plaque $[5,6]$.

The finite element method has been widely used to study the stent expansion and stent-artery interaction, but most documented studies focused on balloon-expandable stents [7-10]. It was worth noting that Early et al. studied the deployment of balloonexpandable stent subjected to bending found in the peripheral artery [11]. The self-expanding Nitinol stent, with its unique superelastic characteristics and improved clinical outcomes in SFA is drawing more attention on the modeling of its expansion and interaction with artery [12-15]. However, the shape of plaque was usually simplified or not included at all. For example, Harvey simulated the deployment of Nitinol stent in a realistic human peripheral artery subjected to pulsatile loading conditions, without considering the existence of plaque [12].

In this study, a PROTÉGÉ ${ }^{\mathrm{TM}}$ GPS $^{\mathrm{TM}}$ self-expanding Nitinol stent was deployed into a stenosed artery and the immediate outcome of stenting was quantified through finite element analysis. The material properties of the artery were measured in each of its three layers (intima, media, and adventitia). The stent dogboning effect, tissue prolapse, lumen gain, and arterial stress distribution were evaluated. The effect of lesion calcification was assessed.

\footnotetext{
${ }^{1}$ Corresponding author.

Manuscript received January 11, 2011; final manuscript received February 18 2012; published online April 5, 2012. Assoc. Editor: Erol Sancaktar.
}

\section{Materials and Methods}

A three-layered artery with a length of $30 \mathrm{~mm}$, inner diameter of $9 \mathrm{~mm}$, and total wall thickness of $1 \mathrm{~mm}$ was considered (Fig. 1). The thickness ratio of intima/media/adventitia was $1 / 6 / 3$ adapted from the observations of Schulze-Bauer et al. [16]. A $16 \mathrm{~mm}$-long eccentric plaque caused a $50 \%$ stenosis. The eccentricity, defined as the maximum ratio of the thickness at the narrowest occlusion, was 2. A PROTÉGÉ ${ }^{\mathrm{TM}} \mathrm{GPS}^{\mathrm{TM}}$ selfexpanding Nitinol stent (ev3 Inc., Plymouth, MN), which is shown in Fig. 1, was deployed in the stenosed artery to improve the lumen size and restore the blood flow. The stent is composed of 18 units along the circumferential direction and 9 units along the axial direction and has a nominal diameter of $10 \mathrm{~mm}$, length of $20 \mathrm{~mm}$, and strut thickness of $0.22 \mathrm{~mm}$. The stent was initially confined inside a sheath at the tip of the catheter and delivered to the target lesion. Then it self-expanded to compress the lesion and regained the lumen after the removal of the sheath.

The GPS ${ }^{\mathrm{TM}}$ stent was meshed into 7248 beam elements (B31), which account for large axial deformation as well as transverse shear deformation. The use of beam elements in stenting simulation has been validated through experiments by Kim et al. [17]. The sheath was represented by 26 reduced-integration shell elements (S4R). The artery and plaque were discretized into 43,687 and 13,122 reduced-integration eight-node brick elements (C3D8R), respectively.

The GPS ${ }^{\mathrm{TM}}$ stent is made of Nitinol, a superelastic material with phase transformation between austenite phase and martensite phase (Fig. 2). The material properties, adopted from the testing data from unspecified Nitinol stent [15], were implemented in the ABAQUS (Dassault Systèmes Simulia Corp., Providence, RI) user material subroutine (VUMAT).

Both artery and plaque were modeled as isotropic hyperelastic material through a polynomial strain energy potential function as

$$
U=\sum_{i+j=1}^{N} C_{i j}\left(I_{1}-3\right)^{i}\left(I_{2}-3\right)^{j}
$$



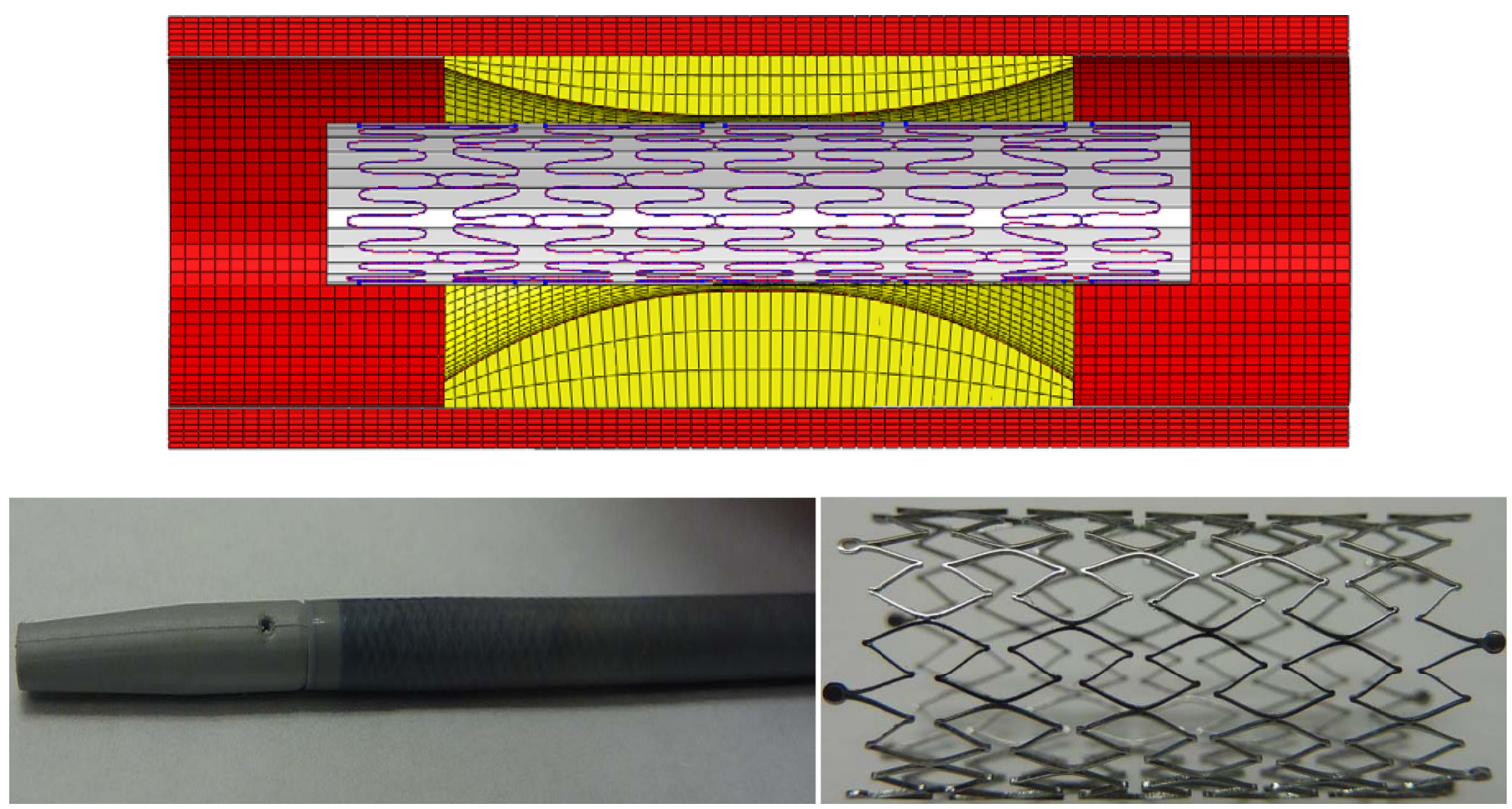

Fig. 1 Computational model of a GPS ${ }^{\mathrm{TM}}$ stent, confined inside a sheath, inside a stenosed artery (top), photos of the GPS ${ }^{\text {TM }}$ stent loaded in the tip of catheter and then self-expanded after the sheath removal (bottom)

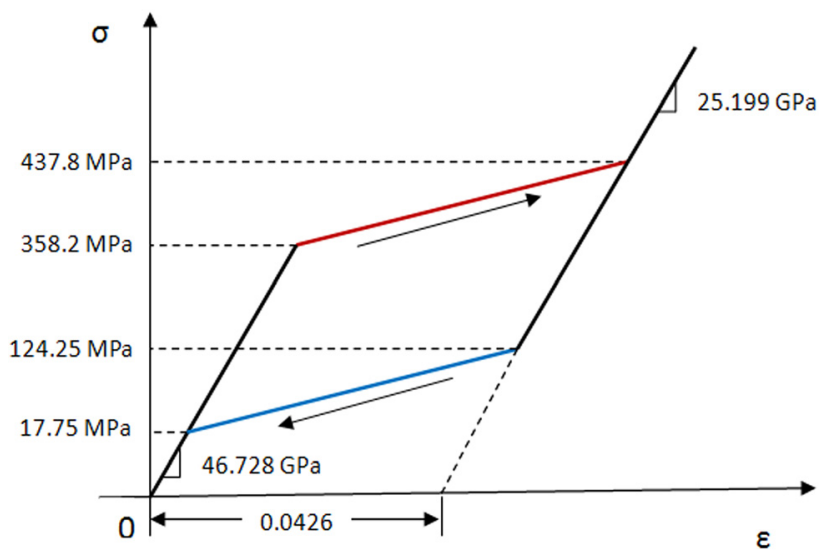

Fig. 2 The stress-driven superelastic behavior of Nitinol

where $C_{i j}$ are material coefficients determined from the experimental data, while $I_{1}$ and $I_{2}$ are the first and second invariant of the Cauchy-Green tensor in terms of principal stretch ratios $\lambda_{i}$ as

$$
I_{1}=\lambda_{1}^{2}+\lambda_{2}^{2}+\lambda_{3}^{2}, \quad I_{2}=\lambda_{1}^{-2}+\lambda_{2}^{-2}+\lambda_{3}^{-2}
$$

Axial and circumferential strips of the intima, media, and adventitia layer of the human aorta were obtained from a $9 \mathrm{~mm}$ CryoValve $^{\circledR}$ aortic valve allograft (CryoLife Inc., Kennesaw, GA). After the separation of three layers, three test specimens per layer were obtained for circumferential tensile testing. For the axial direction, only one strip of intima was appropriate to be tested, three and two strips were obtained for the media and adventitia layer, respectively. Preconditioning up to a strain of 0.35 [18] was used to establish a steady mechanical response in each layer of the aorta. The invariant-based constitutive function described above was used to fit the averaged test data for each layer along the circumferential direction. The obtained material coefficients were listed in Table 1. To study the effect of plaque calcification on the performance of stenting, two stages of plaques were adopted from the publications $[6,19]$ and added to the Table 1 . The material properties of both the artery and plaque were plotted in the Fig. 3 .

Uniform displacement boundary condition was used to crimp the GPS ${ }^{\mathrm{TM}}$ stent into the sheath. After the stent reached the target lesion, a linear ramping velocity of $4 \mathrm{~m} / \mathrm{s}$ was applied onto the sheath to release the self-expanding stent. The general contact algorithm with a friction coefficient of 0.15 was applied among stent, stenosed artery, and sheath.

\section{Results}

The combination of arterial wall stretching and plaque compression is the main factor leading to the lumen gain after stenting $[20,21]$. After the GPS ${ }^{\mathrm{TM}}$ stent self-expanded in an artery with a soft plaque, the arterial diameter was stretched from $9 \mathrm{~mm}$ to $11.18 \mathrm{~mm}$, while the plaque was compressed by $0.92 \mathrm{~mm}$ in total thickness at the narrowest occlusion, as shown in Fig. 4. The minimum lumen diameter was then increased from $4.50 \mathrm{~mm}$ to $7.60 \mathrm{~mm}$, which corresponded to an instant lumen gain of $3.10 \mathrm{~mm}$ and a residual stenosis of $15.56 \%$. The arterial stretch, measured as the difference between the minimum arterial diameter

Table 1 Hyperelastic material coefficients for both artery and plaque

\begin{tabular}{|c|c|c|c|c|c|c|c|}
\hline & $\mathrm{C}_{10}(\mathrm{MPa})$ & $\mathrm{C}_{01}(\mathrm{MPa})$ & $\mathrm{C}_{11}(\mathrm{MPa})$ & $\mathrm{C}_{20}(\mathrm{MPa})$ & $\mathrm{C}_{02}(\mathrm{MPa})$ & $\mathrm{C}_{30}(\mathrm{MPa})$ & $\mathrm{C}_{03}(\mathrm{MPa})$ \\
\hline \multicolumn{8}{|l|}{ Artery } \\
\hline Intima & 0.02412 & & & 0.03413 & & & \\
\hline Media & 0.03828 & & & 0.01885 & & 0.02067 & \\
\hline Adventitia & 0.02962 & & & -0.00676 & & 0.01950 & \\
\hline Soft plaque [19] & 0.04 & & & & 0.003 & & 0.02976 \\
\hline Calcified plaque [6] & -0.49596 & 0.50661 & 1.19353 & 3.6378 & & 4.73725 & \\
\hline
\end{tabular}




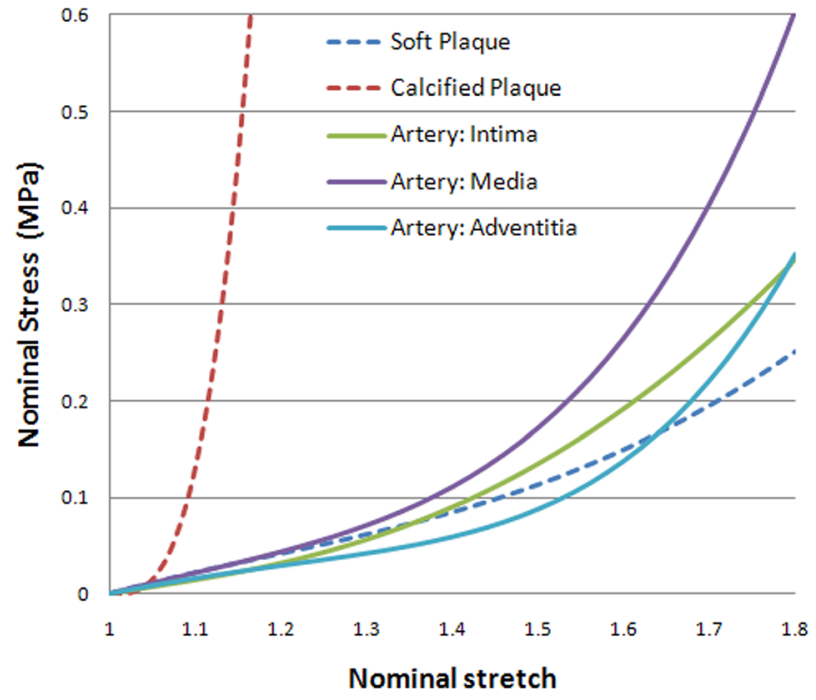

Fig. 3 Stress-stretch relationships for both artery and plaque

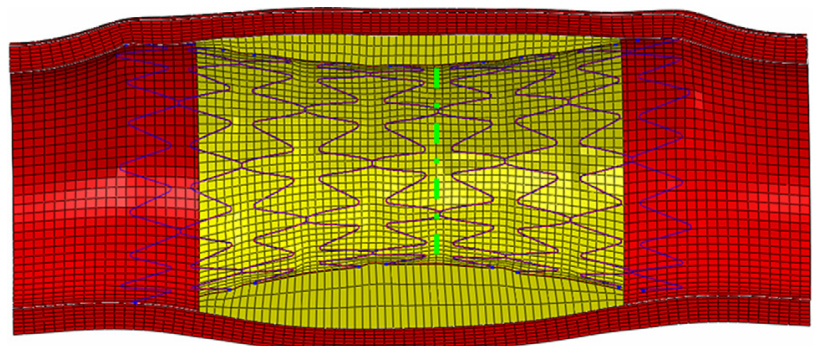

Fig. 4 The stented artery with soft plaque (cut view)

before stenting and after stenting, contributed to $70.32 \%$ of instant lumen gain. For a calcified plaque, the arterial stretch and plaque compression reduced significantly. The arterial stretch was $0.93 \mathrm{~mm}$, corresponding to a $10 \%$ diametric variation. The plaque compression was only $0.03 \mathrm{~mm}$ in total thickness, compared with the $0.92 \mathrm{~mm}$ for the soft plaque. The plaque compression only accounted for $3 \%$ of the diametric lumen gain. The $39.33 \%$ residual stenosis existed immediately after stent deployment due to the lesion calcification, which did not satisfy the desired residual stenosis standard of $30 \%$ or less [22,23]. A pre- or post-dilation of calcified plaque is necessary to achieve a larger lumen gain and a corresponding less residual stenosis.

Due to the mesh configuration of the stent, tissue prolapsed in open space between struts. The tissue prolapse was quantified as the difference between the radial displacement of one point on the tissue surface and the maximum radial displacement of tissue surface bounded by two adjacent struts. The peak tissue prolapse occurred around the most stenotic region, along the dotted line highlighted in Fig. 4. The circumferential variations of the tissue prolapse depend on the open strut design, the thickness, and material properties of the plaque. Figure 5 compared the prolapse of stented artery along the dotted line for both soft and calcified plaque. There are total six struts along the whole dotted circle. The starting angular position $\left(0^{\circ}\right)$ corresponded to the strut location closest to thinnest edge of plaque, as shown in the cross-section view in Fig. 5. The maximum prolapse occurred around the fifth strut close to the thickest edge of plaque, same location for both plaque types. The maximum tissue prolapse is $0.227 \mathrm{~mm}$ for stented soft plaque, compared with $0.204 \mathrm{~mm}$ for calcified plaque.

It is also clear that the self-expanding GPS ${ }^{\mathrm{TM}}$ stent conformed to the lesion geometry and exhibited a dogbone shape with a larger size at distal ends than at the center, as shown in Fig. 4. The
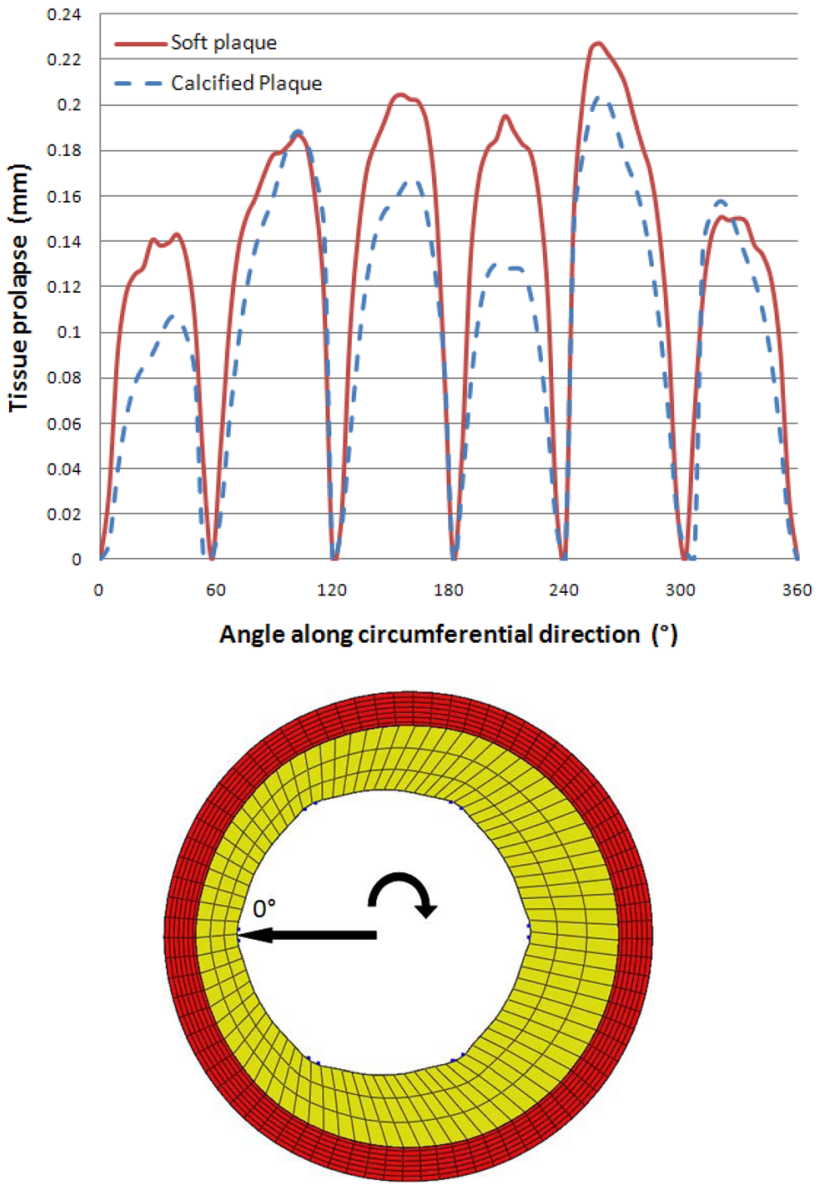

Fig. 5 The peak tissue prolapse distribution (top) located at central region of the plaque, and the cross section view (bottom)

diameter at the center of the stent was $7.62 \mathrm{~mm}$, while the distal diameters were $9.96 \mathrm{~mm}$ and $10.05 \mathrm{~mm}$, respectively. The dogboning effect was more pronounced in the calcified plaque as listed in the Table 2. Dogboning factor, defined as the relative difference between the central diameter and the average diameter at two ends, was $23.84 \%$ for the soft plaque, compared with $48.38 \%$ for the calcified plaque. Due to the incomplete expansion, the stent length was $21.68 \mathrm{~mm}$ immediately after stenting calcified plaque, which was longer than its nominal length of $20 \mathrm{~mm}$. It is worth noting that the proximal end was slightly smaller than the distal end. This could be explained by the longer span between the edge of the plaque and the stent end at the proximal site.

The dogbone shape of the stent might cause arterial wall stress concentrations at the ends of the stent. Figure 6 has depicted the wall stress distributions on each layer of the artery for both soft and calcified plaque cases. The arterial stress concentration was obviously higher especially at the central region of the lesion for the soft plaque case, whereas edge stress concentration was more intense for the calcified plaque. This might be explained by the deformability of the plaque. Less deformation in the calcified plaque led to a pronounced dogbone shape of the stent and thus caused poking at both stent extremities, which might dissect the arterial wall, lead to restenosis, or fracture of the stent [24]. The maximum principal stress of $0.101 \mathrm{MPa}$ was found on the central section of the media layer underneath the thin side of soft plaque; however, for the calcified plaque case, the peak principal stress was found on the medial layer underlying the stent end, and the magnitude was reduced to $0.075 \mathrm{MPa}$. For different arterial layers, the media was subjected to relatively high stresses in all cases, serving as load bearing components, and adventitia undertook the 
Table 2 The Deployed GPS ${ }^{\mathrm{TM}}$ Stent Dimension

\begin{tabular}{lcrr}
\hline \hline Type of plaque & Central diameter & Proximal diameter & Distal diameter \\
\hline Soft & $7.62 \mathrm{~mm}$ & $9.96 \mathrm{~mm}$ & $10.05 \mathrm{~mm}$ \\
Calcified & $5.42 \mathrm{~mm}$ & $10.34 \mathrm{~mm}$ & $23.84 \%$ \\
\hline \hline
\end{tabular}

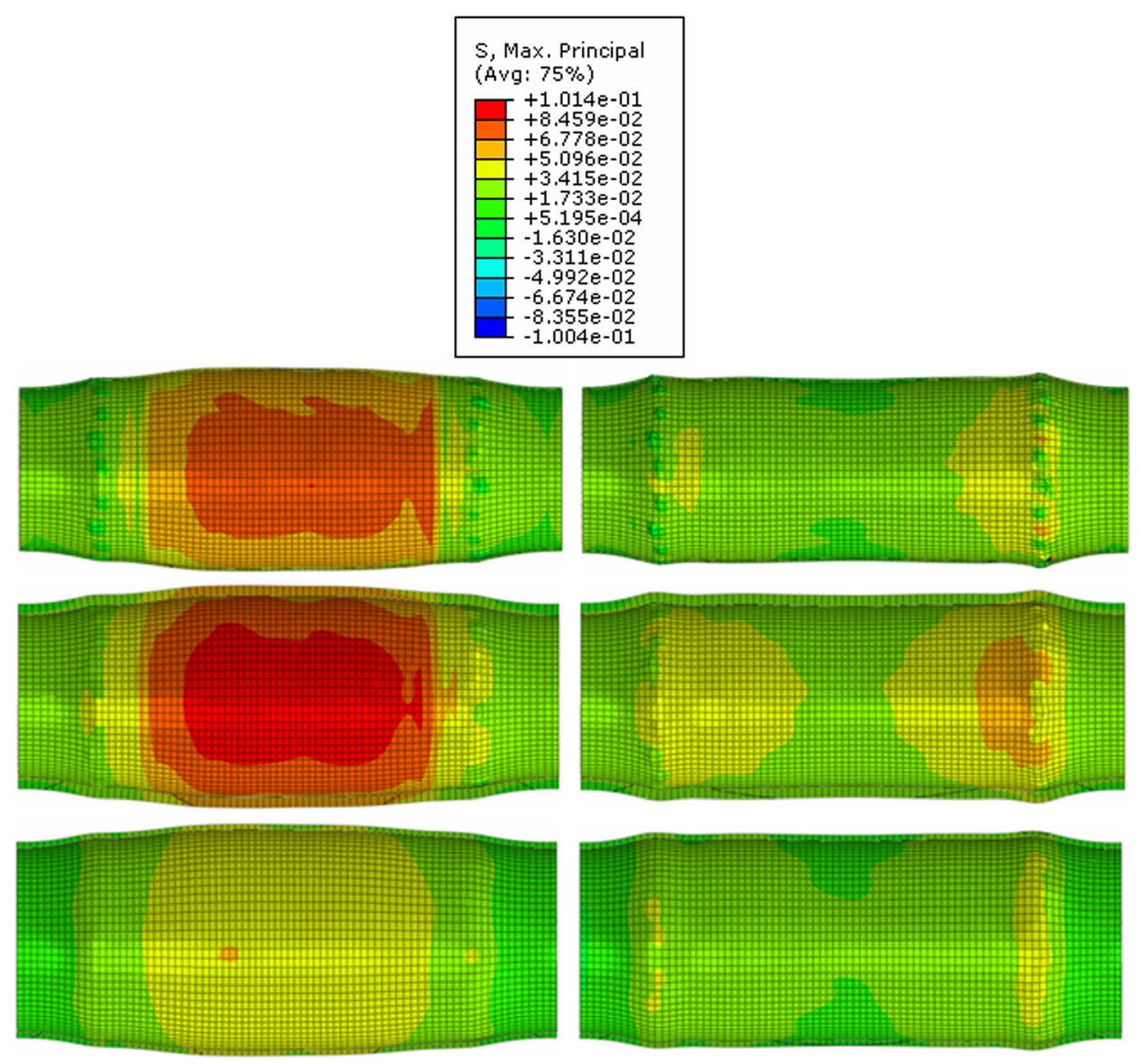

Fig. 6 Stent induced maximum principal stress map on the intima (top), media (middle), and adventitia (bottom) layer of the artery with soft plaque (left) and calcified one (right)

lowest stresses. The percentage of intimal volume where the maximum principal stress exceeds $0.06 \mathrm{MPa}$, the physiological stress level [25], was $16.21 \%$ in the case of soft plaque, compared with $0.02 \%$ in the case of calcified plaque. The percentage of media volume exceeding the stress level of $0.06 \mathrm{MPa}$ was $22.09 \%$ in the case of soft plaque, compared with $0.67 \%$ in the case of calcified plaque. This might be explained by that calcified lesion absorbed more energy and protected the host artery.

\section{Discussions and Conclusions}

Self-expanding stents usually have less radial stiffness and do not reach their nominal dimentions immediately after their deployment [26]. It is considered as a successful procedure if the immediate residual stenosis is less than $30 \%[22,23]$. This will not be easy for stenting a calcified plaque without pre- or postdilation. Our results have demonstrated that a calcified lesion is hard to be reshaped, which affects the outcome of stenting. This agrees with the documented clinical observation [27], which states that full expansion of the stent, especially the central region, is most pronounced in artery with soft lesion, and least pronounced in artery with calcified plaques.

Our results have shown that tissue stiffness is inversely proportional to the tissue prolapse. Larger prolapse occurred in the stent- ing of soft lesion, which could reduce lumen gain and disrupt the flow dynamics leading to the occurrence of restenosis $[28,29]$ or embolization [30]. Calcified lesion stenting induced less tissue prolapse, which may slightly remedy for the acute lumen gain. In summary, the efficiency of stenting to restore blood flow depends on the combination of plaque compression, arterial stretch, and tissue prolapse.

In our work, the incomplete expansion of self-expanding Nitinol stent exhibited a dogbone shape even for the soft plaque, which is attributed to the plaque shape and properties [31] and relatively lower radial scaffolding ability of Nitinol material [14]. This may be compensated by the plateaulike superelasticity of Nitinol, which allows for a late continuous expansion until the stent reaches its nominal dimension [32]. This speculation of late expansion has been validated by clinical studies [33-35], which showed that the continued expansion of a Nitinol stent mitigated its initial incomplete expansion. Clinical observations by Lownie et al. reported that the minimal late expansion occurred on calcified plaque [34]. This can be explained by the stiffness of a calcified lesion.

The dogbone shape of the stent poked into the arterial wall and induced stress concentrations at the ends of the stent. Local stress concentrations may initiate the neointimal proliferation or edge dissection and increase the risk of complication [36-38]. The 
incomplete expansion of the Nitinol stent led to a larger stress concentration at the ends of stents deployed in the artery with calcified plaque. This indicates a higher risk to dissect the arterial wall, leading to restenosis or fracture of the stent [24]. The geometrical discontinuity between plaque and artery at the plaque ends will aggravate the arterial stress concentrations as demonstrated in our previous work [39]. Except the above mentioned stent end regions, the wall stress distribution at each layer of the artery demonstrated a lower arterial stress profile when plaques were calcified. This is due to the large stiffness of the calcified lesion, which could absorb more transmitted energy with a small amount of deformation. It indicates that the stiffer lesion protected the host artery through mitigating the arterial stress and the occurrence of neointimal hyperplasia accordingly [11]. Our speculations on the influence of lesion calcification agrees with the clinical observations such that less neointimal hyperplasia was found on calcified plaque compared with the soft one [40]. Despite the mitigation of arterial stress by the calcified plaque, the desired lumen gain with minimal dogboning after stenting calcified lesion requires pre- and/or post-surgical management [27].

\section{Limitations}

In this work, the expansion of a self-expanding GPS $^{\mathrm{TM}}$ stent and its interaction with diseased lesion was quantified to understand the impact of plaque calcification on stenting outcomes. The self-expanding behavior of the GPS ${ }^{\mathrm{TM}}$ stent was obtained through implementing the material properties of Nitinol material. The three-layered structure of the artery was considered in our model. However, each layer was assumed as the uniform thickness. Calcification morphology and size such as a combination of soft and calcified plaque vary in the patient population. The patientspecific artery with plaque composition will cause variation on the stress distribution and stent-artery interaction in terms of arterial stretch, lesion damage, tissue prolapse, and dogboning effect. For example, a calcified plaque cap combined with lipid pool could lead to stress concentration in the cap itself, especially at the shoulder location [41]. Moreover, the main damage mechanism of calcified plaque is rupture [42], which will be included in our future studies. The adopted Nitinol properties in this work were based on the test data from unspecified Nitinol stents [15]. The temperature-driven shape memory properties of Nitinol were not considered in this work. The variation in the Nitinol material properties, if any, will lead to the altered absolute value presented in this work, not the qualitative trend analysis.

Aortic allograft samples were characterized in this work, which is softer than the human peripheral vessel specimens [42]. Considering the inherent variation in tissue properties, as well as the comparative nature of this work, the material properties obtained in this work can be justified to study the effect of plaque calcification.

\section{Acknowledgment}

The authors are grateful for funding from the National Science Foundation under Grant No. 0926880 and No. 0811250.

\section{References}

[1] Duda, S. H., Bosiers, M., Pusich, B., Huttl, K., Oliva, V., Muller-Hulsbeck, S., Bray, A., Luz, O., Remy, C., Hak, J. B., and Beregi, J. P., 2002, "Endovascular Treatment of Peripheral Artery Disease With Expanded PTFE-Covered Nitinol Stents: Interim Analysis From a Prospective Controlled Study," Cardiovasc. Intervent. Radiol., 25(5), pp. 413-418.

[2] Bosiers, M., Torsello, G., Gissler, H. M., Ruef, J., Muller-Hulsbeck, S., Jahnke, T., Peeters, P., Daenens, K., Lammer, J., Schroe, H., Mathias, K., Koppensteiner, R., Vermassen, F., and Scheinert, D., 2009, "Nitinol Stent Implantation in Long Superficial Femoral Artery Lesions: 12-Month Results of the DURABILITY I Study," J. Endovasc. Ther., 16(3), pp. 261-269.

[3] Schillinger, M., Sabeti, S., Loewe, C., Dick, P., Amighi, J., Mlekusch, W., Schlager, O., Cejna, M., Lammer, J., and Minar, E., 2006, "Balloon Angioplasty Versus Implantation of Nitinol Stents in the Superficial Femoral Artery," N. Engl. J. Med., 354(18), pp. 1879-1888.
[4] Zahedmanesh, H., and Lally, C., 2009, "Determination of the Influence of Stent Strut Thickness Using the Finite Element Method: Implications for Vascular Injury and In-Stent Restenosis," Med. Biol. Eng. Comput., 47(4), pp. 385-393.

[5] Morton, A. C., Crossman, D., and Gunn, J., 2004, "The Influence of Physical Stent Parameters Upon Restenosis," Pathol. Biol., 52(4), pp. 196-205.

[6] Pericevic, I., Lally, C., Toner, D., and Kelly, D. J., 2009, "The Influence of Plaque Composition on Underlying Arterial Wall Stress During Stent Expansion: The Case for Lesion-Specific Stents," Med. Eng. Phys., 31(4), pp. 428-433.

[7] Auricchio, F., Di Loreto, M., and Sacco, E., 2001, "Finite-Element Analysis of a Stenotic Artery Revascularization Through a Stent Insertion," Comput. Methods Biomech. Biomed. Eng., 4(3), pp. 249-263.

[8] Migliavacca, F., Petrini, L., Colombo, M., Auricchio, F., and Pietrabissa, R. 2002, "Mechanical Behavior of Coronary Stents Investigated Through the Finite Element Method," J. Biomech., 35(6), pp. 803-811.

[9] Wu, W., Wang, W. Q., Yang, D. Z., and Qi, M., 2007, "Stent Expansion in Curved Vessel and Their Interactions: A Finite Element Analysis," J. Biomech., 40(11), pp. 2580-2585.

[10] Liang, D. K., Yang, D. Z., Qi, M., and Wang, W. Q., 2005, "Finite Element Analysis of the Implantation of a Balloon-Expandable Stent in a Stenosed Artery," Int. J. Cardiol., 104(3), pp. 314-318.

[11] Early, M., Lally, C., Prendergast, P. J., and Kelly, D. J., 2009, "Stresses in Peripheral Arteries Following Stent Placement: A Finite Element Analysis," Comput. Methods Biomech. Biomed. Eng., 12(1), pp. 25-33.

[12] Harvey, S., 2010, "Comprehensive Nitinol Stent Finite Element Numerical Simulations: From Shape Setting and Deployment, Through Fatigue Life Predictions in a Realistic Peripheral Human Artery Subjected to Pulsatile and Articulation Loading Conditions," Proceedings of the International Conference on Shape Memory and Superelastic Technologies, Pacific Grove, CA.

[13] Conti, M., Auricchio, F., De Beule, M., and Verhegghe, B., 2009, "Numerical Simulation of Nitinol Peripheral Stents: From Laser-Cutting to Deployment in a Patient Specific Anatomy," Proceedings of the 8th European Symposium on Martensitic Transformations, Prague, Czech Republic.

[14] Wu, W., Qi, M., Liu, X. P., Yang, D. Z., and Wang, W. Q., 2007, "Delivery and Release of Nitinol Stent in Carotid Artery and Their Interactions: A Finite Element Analysis," J. Biomech., 40(13), pp. 3034-3040.

[15] Rebelo, N., Walker, N., and Foadian, H., 2001, "Simulation of Implantable Nitinol Stents," Proceedings of the 2001 Abaqus Users conference, Providence, RI.

[16] Schulze-Bauer, C. A., Morth, C., and Holzapfel, G. A., 2003, "Passive Biaxial Mechanical Response of Aged Human Iliac Arteries," J. Biomech. Eng., 125(3), pp. 395-406.

[17] Kim, J. H., Kang, T. J., and Yu, W. R., 2008, "Mechanical Modeling of SelfExpandable Stent Fabricated Using Braiding Technology," J. Biomech., 41(15), pp. 3202-3212.

[18] Holzapfel, G. A., Sommer, G., Gasser, C. T., and Regitnig, P., 2005 , "Determination of Layer-Specific Mechanical Properties of Human Coronary Arteries With Nonatherosclerotic Intimal Thickening and Related Constitutive Modeling," Am. J. Physiol. Heart Circ. Physiol., 289(5), pp. H2048-2058.

[19] Migliavacca, F., Petrini, L., Massarotti, P., Schievano, S., Auricchio, F., and Dubini, G., 2004, "Stainless and Shape Memory Alloy Coronary Stents: A Computational Study on the Interaction With the Vascular Wall," Biomech. Model. Mechanobiol., 2(4), pp. 205-217.

[20] Albrecht, D., Kaspers, S., Fussl, R., Hopp, H. W., and Sechtem, U., 1996 "Coronary Plaque Morphology Affects Stent Deployment: Assessment by Intracoronary Ultrasound," Cathet. Cardiovasc. Diagn., 38(3), pp. 229-235.

[21] Tsutsumi, M., Aikawa, H., Onizuka, M., Iko, M., Kodama, T., Nii, K., Hamaguchi, S., Etou, H., Sakamoto, K., and Kazekawa, K., 2008, "Carotid Artery Stenting for Calcified Lesions,” AJNR Am. J. Neuroradiol., 29(8), pp. 1590-1593.

[22] Elezi, S., Kastrati, A., Neumann, F. J., Hadamitzky, M., Dirschinger, J., and Schomig, A., 1998, "Vessel Size and Long-Term Outcome After Coronary Stent Placement," Circulation, 98(18), pp. 1875-1880.

[23] Krankenberg, H., Schluter, M., Steinkamp, H. J., Burgelin, K., Scheinert, D., Schulte, K. L., Minar, E., Peeters, P., Bosiers, M., Tepe, G., Reimers, B., Mahler, F., Tubler, T., and Zeller, T., 2007, "Nitinol Stent Implantation Versus Percutaneous Transluminal Angioplasty in Superficial Femoral Artery Lesions up to $10 \mathrm{~cm}$ in Length: The Femoral Artery Stenting Trial (FAST)," Circulation, 116(3), pp. 285-292.

[24] Taneja, M., Tay, K. H., Sebastian, M., Pasupathy, S., Lin, S. E., Teo, T., Low, R., Irani, F., G., Chng, S. P., Dewan, A., and Tan, B. S., 2009, "Self-Expanding Nitinol Stents in Recanalisation of Long-Length Superficial Femoral Artery Occlusions in Patients With Critical Limb Ischaemia," Singapore Med. J., 50(12), pp. 1184-1188.

[25] Thubrikar, M. J., 2007, "Stress-Concentration in the Artery I," Vascular Mechanics and Pathology, Springer, New York, Chap. 6.

[26] Roguin, A., Grenadier, E., Linn, S., Markiewicz, W., and Beyar, R., 1999, "Continued Expansion of the Nitinol Self-Expanding Coronary Stent: Angiographic Analysis and 1-Year Clinical Follow-Up," Am. Heart J., 138(2 Pt 1), pp. 326-333.

[27] Willfort-Ehringer, A., Ahmadi, R., Gruber, D., Gschwandtner, M. E., Haumer, A., Haumer, M., and Ehringer, H., 2004, "Arterial Remodeling and Hemodynamics in Carotid Stents: A Prospective Duplex Ultrasound Study Over 2 Years," J. Vasc. Surg., 39(4), pp. 728-734.

[28] Hong, M. K., Park, S. W., Lee, C. W., Kang, D. H., Song, J. K., Kim, J. J., and Park, S. J., 2000, "Long-Term Outcomes of Minor Plaque Prolapsed Within Stents Documented With Intravascular Ultrasound," Cathet. Cardiovasc. Interv., 51(1), pp. 22-26. 
[29] Jang, I. K., Tearney, G., and Bouma, B., 2001, "Visualization of Tissue Prolapse Between Coronary Stent Struts by Optical Coherence Tomography Comparison With Intravascular Ultrasound," Circulation, 104(22), p. 2754.

[30] Siewiorek, G. M., Finol, E. A., and Wholey, M. H., 2009, "Clinical Significance and Technical Assessment of Stent Cell Geometry in Carotid Artery Stenting," J. Endovasc. Ther., 16(2), pp. 178-188.

[31] Kan, H. C., 2010, "Investigation of Plaque Effects on CardiovascularStent System," Proceedings of the 4th International Conference on Bioinformatics and Biomedical Engineering (iCBBE), Chengdu, P. R. C.

[32] Melzer, A., and Stoeckel, D., 2010, "Function and Performance of Nitinol Vascular Implants," Open Med. Devices J., 2, pp. 32-41.

[33] Sanmartin, M., Goicolea, J., Alfonso, F., Escaned, J., Flores, A. A., FernandezOrtiz, A., Banuelos, C., Hernandez-Antolin, R. A., and Macaya, C., 2002 "Implications of Late Expansion of Self-Expanding Stents on Neointimal Response: A Serial Study With Intravascular Ultrasound," Rev. Esp. Cardiol., 55(1), pp. 16-24.

[34] Lownie, S. P., Pelz, D. M., Lee, D. H., Men, S., Gulka, I., and Kalapos, P. 2005, "Efficacy of Treatment of Severe Carotid Bifurcation Stenosis by Using Self-Expanding Stents Without Deliberate Use of Angioplasty Balloons," AJNR Am. J. Neuroradiol., 26(5), pp. 1241-1248.

[35] Zhao, H. Q., Nikanorov, A., Virmani, R., Jones, R., Pacheco, E., and Schwartz, L. B., 2009, "Late Stent Expansion and Neointimal Proliferation of Oversized Nitinol Stents in Peripheral Arteries," Cardiovasc. Intervent. Radiol., 32(4), pp. $720-726$
[36] Timmins, L. H., Meyer, C. A., Moreno, M. R., and Moore, J. E., 2008, "Effects of Stent Design and Atherosclerotic Plaque Composition on Arterial Wall Biomechanics," J. Endovasc. Ther., 15(6), pp. 643-654.

[37] Colombo, A., Stankovic, G., and Moses, J. W., 2002, "Selection of Coronary Stents," J. Am. Coll. Cardiol., 40(6), pp. 1021-1033.

[38] Liao, R., Green, N. E., Chen, S. Y., Messenger, J. C., Hansgen, A. R., Groves, B. M., and Carroll, J. D., 2004, "Three-Dimensional Analysis of in vivo Coronary Stent-Coronary Artery Interactions," Int. J. Card. Imaging, 20(4), pp. 305-313.

[39] Gu, L. X., Zhao, S. J., Muttyam, A. K., and Hammel, J. M., 2010, "The Relation Between the Arterial Stress and Restenosis Rate After Coronary Stenting," J. Med. Devices, 4(3), 031005.

[40] Shimada, Y., Kataoka, T., Courtney, B. K., Morino, Y., Bonneau, H. N., Yock, P. G., Grube, E., Honda, Y., and Fitzgerald, P. J., 2006, "Influence of Plaque Calcium on Neointimal Hyperplasia Following Bare Metal and Drug-Eluting Stent Implantation,” Cathet. Cardiovasc. Interv., 67(6), pp. 866-869.

[41] Veress, A. I., Vince, D. G., Anderson, P. M., Cornhill, J. F., Herderick, E. E., Klingensmith, J. D., Kuban, B. D., Greenberg, N. L., and Thomas, J. D., 2000, "Vascular Mechanics of the Coronary Artery," Z. Kardiol., 89(Suppl. 2), pp. 92-100.

[42] Lally, C., Dolan, F., and Prendergast, P. J., 2005, "Cardiovascular Stent Design and Vessel Stresses: A Finite Element Analysis," J. Biomech., 38(8), pp. $1574-1581$. 